\title{
Green synthesis of chalcone derivatives via Suzuki coupling
}

\author{
Lucas Campos Curcino Vieira*, Arlene G. Corrêa
}

Departamento de Química, Universidade Federal de São Carlos, 13565-905, São Carlos, SP - Brazil

*Corresponding author.Tel: +16 33518215, e-mail: lucas_curcino@hotmail.com

Keywords: chalcones, Suzuki coupling, green chemistry

\section{INTRODUCTION}

An important tool used for the construction of C-C bond is the Suzuki reaction, which is based on the coupling between organoboron compounds and organic halides or triflates, catalyzed by palladium in the presence of base. ${ }^{1}$ The reaction is usually conducted in volatile solvents such as tetrahydrofuran and dimethoxyethane in the presence of palladium complexes, which tend to be expensive and difficult to retrieve and recycle ${ }^{1}$. Recently, Suzuki reaction has been performed using ionic liquids and polyethylene glycol (PEG) as alternative solvents. The advantages in the use of PEG include low cost, feasible to recycle, non-toxic and thermal stability, which allows the use of microwave irradiation. In this work, we describe the microwave-assisted synthesis of substituted chalcones (Figure 1) via Suzuki reaction using PEG400 as solvent. $^{2}$

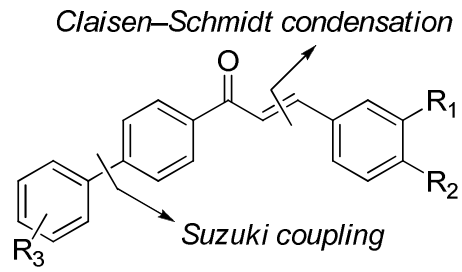

Figure 1. Derivative chalcones synthesized.

\section{RESULTS AND DISCUSSION}

The chalcones were synthesized via the ClaisenSchmidt condensation between substituted benzaldehydes and 4-bromoacetophenone (Scheme $1)^{3}$.

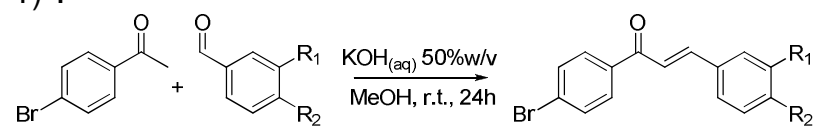

1) $R_{1}, R_{2}=$ methylenedioxy, $95 \%$ 2) $R_{1}, R_{2}=H, 83 \%$

3) $R_{1}=H, R_{2}=O M e, 90 \%$

Scheme 1. Synthesis of chalcones.

The Suzuki coupling between compounds 1-3 with different boronic acids was performed using $\mathrm{PdCl}_{2}$ as a catalyst, potassium fluoride such as base and the solvent used in this reaction was PEG-400. The compounds were obtained with moderate to good yields (Table 1).
Table 1. Synthesis of 4-substituted chalcones.

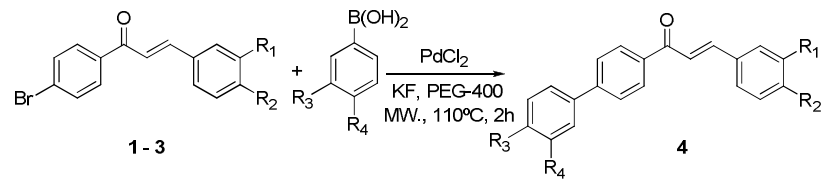

\begin{tabular}{|c|c|c|c|}
\hline Chalcone & $\mathbf{R}_{\mathbf{3}}$ & $\mathbf{R}_{\mathbf{4}}$ & $\begin{array}{c}\mathbf{4}, \mathbf{Y i e l d} \\
\text { (\%) }\end{array}$ \\
\hline $\mathbf{1}$ & $\mathrm{H}$ & $\mathrm{H}$ & 75 \\
\hline $\mathbf{1}$ & $\mathrm{H}$ & $\mathrm{OMe}$ & 83 \\
\hline $\mathbf{1}$ & $\mathrm{H}$ & $\mathrm{Me}$ & 62 \\
\hline $\mathbf{1}$ & $\mathrm{NO}_{2}$ & $\mathrm{H}$ & 70 \\
\hline $\mathbf{1}$ & $\mathrm{F}$ & $\mathrm{OMe}$ & 91 \\
\hline $\mathbf{1}$ & $\mathrm{Me}$ & $\mathrm{F}$ & 81 \\
\hline $\mathbf{1}$ & $\mathrm{methylenedioxy}$ & 71 \\
\hline $\mathbf{2}$ & $\mathrm{OMe}$ & $\mathrm{F}$ & 58 \\
\hline $\mathbf{2}$ & $\mathrm{methylenedioxy}$ & 72 \\
\hline $\mathbf{3}$ & $\mathrm{H}$ & OMe & 57 \\
\hline
\end{tabular}

\section{CONCLUSION}

Employing green conditions, as PEG as solvent and microwave heating, in the Suzuki coupling, we were able to prepare a series of new chalcone derivatives. Furthermore, the use of palladium chloride as catalyst and tolerance of a variety of functional groups is a good advantage for the general usefulness of this methodology.

\section{ACKNOWLEDGEMENTS}

FAPESP, CNPq and CAPES.

\section{REFERENCES}

${ }^{1}$ Myaura, N.; Suzuki, A. Chem. Rev., 1995, 95, 2457.

${ }^{2}$ Namboodiri, V. V., Varma, R. S. Green Chem., 2001, 3, 146.

${ }^{3}$ Borchhardt, D. M.; Mascarello, A.; Chiaradia, L. D.; Nunes, R. J.; Oliva, G.; Yunes, Rosendo A.; Andricopulo, A. D. J. Braz. Chem. Soc. 2010, 21,142 . 